\title{
Surgical treatment of gastric cancer: then and now
}

\author{
Tomasz Olesiński
}

Gastric cancer is one of the most commonly diagnosed cancers found in the world (980,000 new cases in 2008), but its treatment outcomes are poor, particularly in the European Union (EU); only a 25\% survival after 5 years. Despite advances made in combination therapy, the only effective treatment that remains is surgery. The extent of gastric resection and lymphadenectomy, along with reconstruction methods, have systematically evolved over the last 100 years. This paper discusses both present day recommendations and the pathways that were taken enabling modern gastric surgery to develop.

NOWOTWORY J Oncol 2016; 66, 5: 408-414

Key words: gastric cancer, gastrectomy, lymphadenectomy

\section{Introduction}

Although gastric cancer (GC) morbidity has been steadily falling over the last 100 years or so, it still remains the fourth most common cancer in the world; in 2008 there were 980,000 new cases globally, of which 83,000 occurred in the EU and over 5,000 in Poland [1, 2]. Enduring dietary changes and decreases in chronic Helicobacter Pylori infections have led to decreased morbidity in all developed countries of the world within the last 50 years [1]. This however does not translate into a satisfactory rates of those surviving; the 5 year survival for GC in Europe is around 25\%, whereas in Japan it is 70\% [3, 4]. A significant cause for this large difference is that Japan undertakes a screening programme that enables $70 \%$ of diagnoses to be made of early GC, whilst in Poland the rates are never higher than $6.7 \%$. The promising advances made in chemo-/radio-therapies have not altered the fact that still the only method remaining for successfully treating $\mathrm{GC}$ is surgery.

\section{Historical outline}

In spite of the centuries old tradition of performing stomach operations, a breakthrough occurred with the advent of when antiseptics and anaesthesia were discovered. Before the introduction of anaesthesia, attention was however only focused on making a gastric fistula which could extend patient life/survival and halt the spectre of the patient starving to death. The first such fistula was made by an American army doctor, William Beamont in 1822, who was treating a trapper with a bullet wound. A partial gastrectomy, because of cancer, was first performed in Paris on April 1879 by Jules Pean, however the patient died shortly afterwards. Another attempt at removing a gastric tumour was made in Celm on November 1880 by Ludwig Rydygier $[5,6]$; also with no success. It was only Theodor Billroth on January 1881 , who managed to successfully undertake a pylorus resection, including the tumour, followed by anastomy of the proximal stomach to the duodenum; this type of reconstruction is to this day termed a'Billroth I'. Even though the operation was successful, the patient later died because of recurrence. Billroth then encouraged by the experimental work by his pupil Wolffler, subsequently performed an anastomy of the stomach to the jejunum after shutting off and resecting a cancer of the duodenum, thus duodenal passage is bypassed; this procedure being termed the 'Billroth II'. The first successful total gastrectomy (TG) was undertaken in 1897 by Schlatter on a 56 year-old patient who survived for 14 months but then died of metastases. Subsequent attempts however did not proceed so smoothly, where the mortality after such operations was high. It should be remembered that the extent of such interventions relies on 
just removing parts of the pyloric antrum, and it should also be noted that a lymphadenectomy was not even considered. A therapeutic success was then considered as one reducing symptoms and prolonging life by $2-3$ years $[5,6]$. Attempts to improve outcomes were based on changing surgical techniques and methods of reconstruction; but to no avail. For many years the Hoffmeister method remained one of the most popular ways of reconstruction, involving the closing of the stomach at its lesser curvature and anastomy to the greater curvature of the intestinal loop.

High mortality rates, preoperatively, meant that until the 1940 s of the last century gastrectomies were performed extremely rarely. Until 1929, only 62 cases of TG were published throughout the world and the mortality rateexceeded $50 \%$ [7]. The decrease in perioperative mortality occurred due to the introduction of antibiotics, blood transfusion and advances made in analgesia and anaesthesia. Nonetheless, up to the 1970 s, the post-TG mortality risk reached $20 \%$. It was not until advances had been made in enteral and parenteral nutrition, as well as in intensive care, at the end of the 1980s that the mortality rate fell below $5 \%[8,9]$.

\section{The extent of resection}

The beginnings of gastric surgery were mainly devoted to dealing with disease symptoms. Developments in pathological anatomy, physiology and oncology led an evolutionary change in the approach and scope of surgical operations, eventually leading to the concept of regional operating theatres. The aim of surgery is to remove both the tumour and lymph nodes, thereby minimising the risk of relapse. Nevertheless, the growing importance of chemo- and radio-therapy used in combination therapy does not relieve the surgeon of responsibility for curing GC. Following the time when the extent of resection was being maximised, (arising from pinning excessive hopes for curing cancer by these means), compromise solutions are now sought for in trade-offs between the risk of relapse and quality of the patient's life (QoL) after treatment. What then should be the extent of gastric resection/gastrectomy? This should depend on the size, type and location of the tumour. The QoL in TG patients is worse than those when SG is used [10, 11].

If an appropriate macroscopic margin is preserved, then any partial surgical resection does not lower the chances for effecting a cure and it improves the QoL. Evidence for this was provided by prospective studies of Gouzi, Bozzetti and Davies [11-14]. Most researchers consider that 4-5 cm is a safe enough margin for intestinal tumours, but $6-8 \mathrm{~cm}$ for diffuse tumours; according to Lauren [11, 14-16]. A retrospective study by Harrison et al. evaluated 98 patients with cancer in the proximal part of the stomach, (65 after SG and 33 after TG), and found no differences in survival or recurrence rates, however the QoL had not been measured. Indeed, there is no prospective study data in the literature that takes into account QoL in both such groups.
Hundhal et al. summarised treatment outcomes for patients operated on in the USA, during 1985-1996. Only 18\% patients underwent D2 lymphadenectomy; in line with UICC classification of $>15$ lymph nodes/sample. More than half the patients were at clinical stages III and IV of advancement and less than $1 / 3$ had a tumour located in the distal part of the stomach. In spite of the limited indications for partial gastrectomy, a complete excision was undertaken in only $40 \%$ cases [17]. Siewert reported on treatment outcomes in 1654 patients from German and Austrian centres: 30\% tumours were located in the distal part of the stomach, 39.9\% in the middle and $26 \%$ in the proximal [18]. A subtotal distal gastrectomy was performed only in $23.1 \%$ of patients, whilst the others underwent total or total extended gastrectomies for tumours of the gastroesophageal junction. Extending the extent of resection to those neighbouring organs that are infiltrated, increases the risk of complications and mortality during the perioperative period $[19,20]$. However in certain cases of infiltration/invasion, particularly for node-negative stage patients, the chances of recovery are significantly affected [21-24]. Splenectomy and splenopancreatectomy had no effect on survival compared to resection limited by an analogous lesion progression according to the UICC classification [21]. Prospective studies have not yielded any data on the effects of splenectomy on treatment outcomes. Nonetheless, removing lymph nodes from the splenic cavity whilst preserving the organ can prove difficult. A vitally important and still much debated issue is the extent of the lymphadenectomy. The success of Japanese surgeons in treating GC was initially confirmed by retrospective studies and led to defining the range of the so-called standard (D1) and the extended (D2) lymphadenectomies. Furthermore, it is accepted that for correctly assessing the tumour stage, at least 15 lymph nodes are required present for a D1 and at least 25 for a D2. The classification of lymphadenectomy ranges made by the Japanese Research Society for Gastric Cancer is shown in Figure 1. Studies by Maruyama et al. have proved the advantage of performing a D2 lymphadenectomy over D1. The difference in 5-year survival rates was significant; $61.6 \%$ vs $44.3 \%[25,26]$.

The difficult-to-replicate Japanese studies in Western countries have prompted prospective European studies to be undertaken. The largest of these was a study by Bonenkamp et al. (Dutch Gastric Cancer Group), in which 632 patients were randomised into two lymphadenectomy groups: D1 or D2. The differences in 5-year survival proved to be insignificant, nevertheless significant differences were respectively observed for the following: complications ( $25 \%$ vs $43 \%$ ) and perioperative mortality (4\% vs $10 \%$ ) [19]. One drawback pointed out for the Dutch study is the limited experience of surgeons performing the extended lymphadenectomies, which may also increase the risk of complications, including deaths; most of the centres performing less 
than 10 gastric operations annually. The D2 operation was similarly found to be inferior in a study by Cushieri et al. on 400 patients [20]. Upon investigating the sub-groups from these two studies, then the increasing complications and perioperative mortality rates were found to apply to those patients that underwent extended resection for splenectomy and/or distal pancreatectomy. If such cases are excluded from the assessment, then mortality and complications become similar for both groups. Moreover, at clinical stage II and III A, the survival is significantly longer in the D2 group. This is confirmed by an extended lymph node dissection study from Holland [27], a study by Edwards et al. (5-year survival $32 \%$ vs $59 \%$ in favour of D2), Siewert and a German group, where patients at clinical stage II showed $49.2 \%$ vs $19.9 \%$ rates (i.e. a $30 \%$ difference favouring D2) as well as by other Japanese researchers [18, 26-28]. A study by Sano [29] surveyed selected centres specialising in gastric surgery (i.e. above 80 gastrectomies annually) and showed that both D2 and D2+ lymphadenectomies (extended by the paraaortic nodes) can be safely performed by experienced surgeons (mortality $0.8 \%$ ). Evidence is lacking that any further extension of lymphadenectomy improves patient survival, which was confirmed by studies from the Cracow-based centre; Kulig et al. [30, 31].

The standard treatment of gastric adenocarcinoma is currently the complete/almost complete excision of the stomach (a margin/boundary of at least $5 \mathrm{~cm}$ ) together with regional D2 lymphadenectomy. The area of lymphadenectomy can be limited to D1 (lymph nodes around the stomach) for T1N0 advancement. The area of D2 lymphadenectomy includes the lymph nodes of the celiac artery, the left gastric artery, common hepatic artery and the surroundings of the splenic artery along with the hilus lienis (splenic cacity) which in isolated cases may require selective removal of

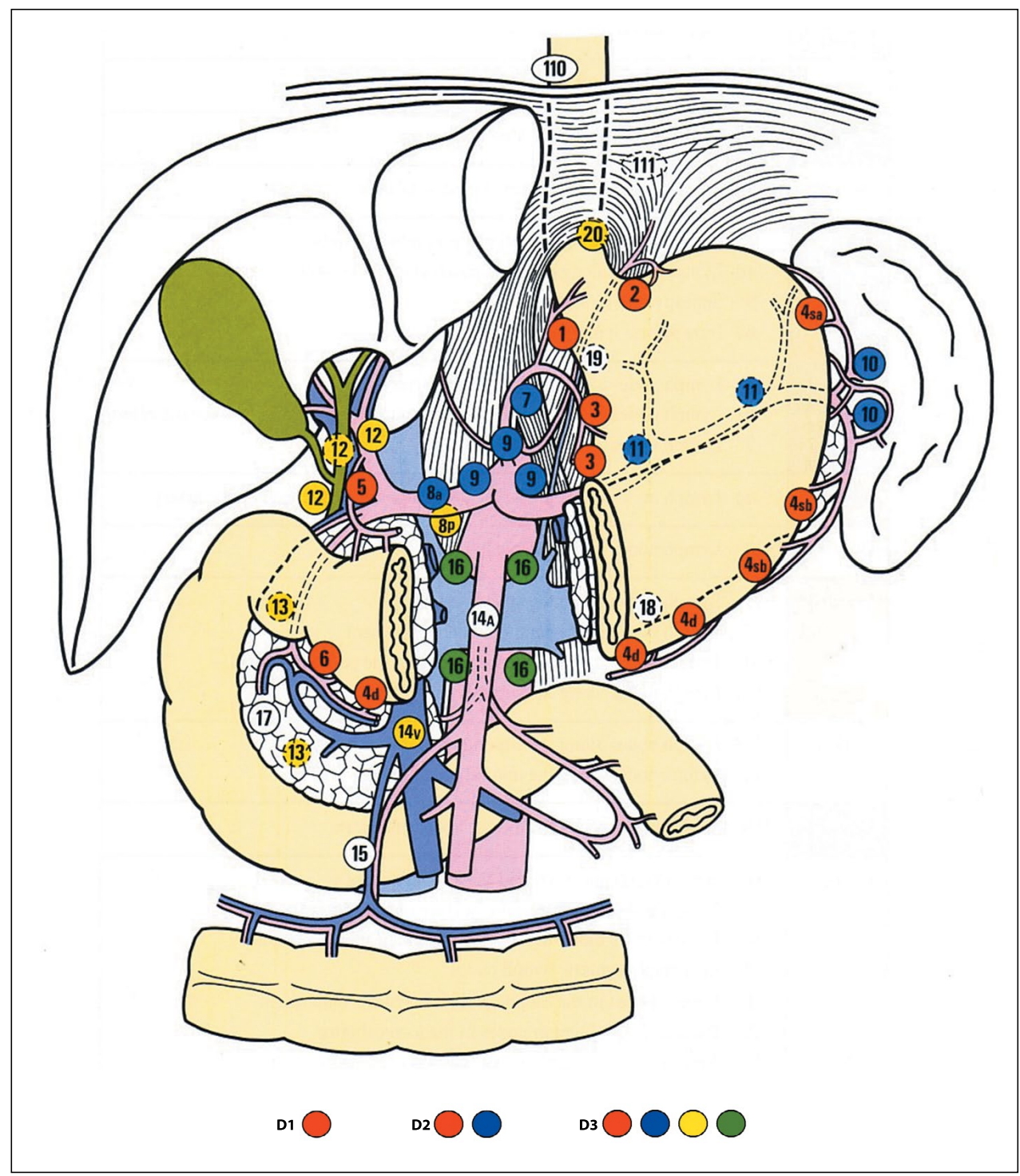

Figure 1. Extent of resected gastric lymph nodes (according to the Japanese Research Society for Gastric Cancer) 
Table I. Surgical treatment of gastric cancer NCCN vs ESMO Consensus Am Coll Surg 2013 [16]

\begin{tabular}{|c|c|}
\hline \multirow[t]{2}{*}{ Resection extent } & Proximal tumour - TG \\
\hline & Distal tumour — SG/TG \\
\hline \multirow[t]{3}{*}{ Lymphadenectomy } & T1N0 - D1 \\
\hline & $\mathrm{T}>1 \mathrm{~N}>0-\mathrm{D} 2$ \\
\hline & $\begin{array}{l}\text { Minimum } 15 \text { lymph nodes in surgical } \\
\text { sample after radical surgery } 25 \text { lymph } \\
\text { nodes }\end{array}$ \\
\hline \multirow[t]{3}{*}{ Organ resection } & Splenectomy - electively NO \\
\hline & Bursectomy — electively NO \\
\hline & $\begin{array}{l}\text { Cholecystectomy - electively NO, } \\
\text { only for cholelithiasis }\end{array}$ \\
\hline Margins & $\begin{array}{l}<5 \mathrm{~cm} \text { ad-hoc studies, cutting into } \\
\text { positive margins ( } \mathrm{R} 1)\end{array}$ \\
\hline \multirow[t]{3}{*}{ Reconstruction } & After SG — Roux-en-Y \\
\hline & After TG - Roux-en-Y \\
\hline & - Roux-en-Y + reservoir \\
\hline \multirow[t]{2}{*}{ Post-surgery nutrition } & Jejunostomy — after TG \\
\hline & TPN - Lack of consesus \\
\hline \multirow[t]{2}{*}{ Others } & Poll — lack of consensus \\
\hline & Routine sealing - lack of consensus \\
\hline
\end{tabular}

the spleen, whilst sparing the pancreas. Obligatory standards of conduct for treating gastric cancer are summed up by the American College of Surgeons (Tab. I) [16]. Despite attempts for globally harmonising standards, there are important differences in how the extents of radical resection are approached between Asia with the US and Europe. In Western countries, the recommended margins for achieving a curative resection (RO) through TG or SG is a $4 \mathrm{~cm}$ minimum according to the NCCN or $5-8 \mathrm{~cm}$ by ESMO or a D1 or D2 lymphadenectomy (without elective pancreatic resection/splenectomy) at a minimum of 15 lymph nodes being present [32-33]. Japanese recommendations give a margin of 2-5 cm depending on the $T$ and $G$ tumour characteristics [34]. Other differences are in the extent of lymphadenectomy. In contrast to the Japanese, recommendations for D1 according to Western countries does not include the lymph nodes of left gastric artery. Such differences make it indeed difficult to compare treatment outcomes (Fig. 1).

\section{Reconstruction methods following total gastrectomy}

The aim of reconstruction in the GI tract is to restore the function of a given resected organ by as far as is possible, so enabling a reversion back to an independent status. Up till now there are 50 ways proposed for reconstruction, post-gastrectomy, but all can be divided into two basic groups according to whether duodenal passage has been preserved or not. Both these approaches can be performed in straightforward fashion and are complemented by constructing an intestinal reservoir pouch. A third group uses double-tract methods which reduces the risk of ischemia as well as linking the benefits arising both from retaining duodenal passage and in constructing an intestinal reservoir pouch.

The method of reconstruction after TG as proposed by Schlatter, [7] consisted of oesophageal anastomosis with the intestinal loop pulled up and when completed by intraintestinal anti-reflux anastomosis, this procedure dominated the 1940s. Unfortunately, most patients reported symptoms of reflux oesophagitis $[35,36]$. Likewise, for these same reasons duodenoesophagostomies, as proposed in 1898 by Brigham and then propagated by Nakayama and Hinze, have now been abandoned. It was only in 1909 that a reconstruction of the Y-loop improved the QoL as proposed by Cesar Roux in Lausanne (originally for SG and later adapted for TG) (Fig. 2). The favourable outcomes achieved by this method had been confirmed by numerous studies in the 1940s. A modification proposed by Orr in 1947 involving anastomosis of the end of the oesophagus to the side of the intestinal loop (intended to reduce tension and improve the blood supply to the anastomosis), ultimately determined today's most popular method for reconstruction of the digestive tract after total gastrectomy [9]. Its main advantage is that it is simple to perform and it effectively prevents reflux of bile into the oesophagus, whereas its disadvantage is the absence of duodenal passage. A reconstruction procedure that preserved duodenal passage was (jejunal segment interposition first undertaken in 1941 by Seo and subsequently modified and propagated by Longmire and Henley (Fig. 3). Maintaining the passage of food through the duodenum allows at least to partially preserve the hormonal regulation of the gastrointestinal tract function as well as providing endoscopic access to the duodenum and bile ducts (Figs. 2, 3) [37-40].

From the time when the Roux-en-Y syndrome was first described by Mathias, greater weight is given to retaining the continuity used to reconstruct the intestinal loop, which is designed to protect against peristaltic wave disorders in the intestine and symptoms of pronounced pseudointestinal obstruction. In the opinion of this study group, such measures when taken improves the patient's QoL, especially in the first year after TG [41]. Apart from restoring gastrointestinal passage another important issue after TG it is to prevent reflex disease arising from the lack of the pylorus and lower oesophageal sphincter. The most effective safeguard appears to be in keeping sufficient distance between the oesophageal-intestinal and biliary anastomosis. A distance of around $7 \mathrm{~cm}$ was originally proposed by Roux for the reconstruction; in the 1950s Wells and Johnston lengthened this to $20-25 \mathrm{~cm}$, whilst nowadays the majority of workers suggest $40-60 \mathrm{~cm}$. In reconstructing intestinal interpositions, whilst maintaining duodenal passage, it was initially postulated that the loop length be is less than $20 \mathrm{~cm}$. 


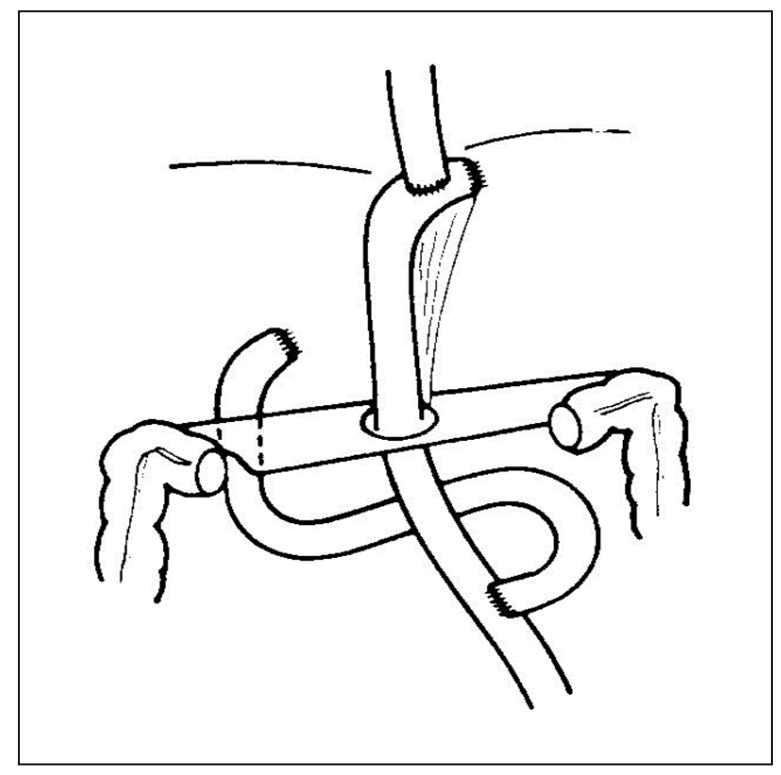

Figure 2. Roux-en-Y reconstruction. No duodenal passage

In 1952, Longmire proposed a longer length, whilst Gutgenam in 1966 confirmed that a loop of $30-35 \mathrm{~cm}$ significantly reduced the risk of reflux disease [38, 39, 42, 43]. An anti-reflux role for jejunoplication was proposed by Schreiber and performed by an end-to-side esophagojejunostomy and using the 'blind' intestinal loop [44, 45]. Gorka however proposed an invagination technique when performing end-to-end esophagojejunostomy through extending the anastomosis to the first line of the intestine at a depth of $4-5 \mathrm{~cm}$, which both protects against leakage during the perioperative period and creates/affords an antireflux mechanism [46]. A favourable anti-reflex outcome can also be obtained by a reconstruction using the ileo-caecal segment and Bauhin's valve. This method was propounded by Lee and Hunnicutt in the early 1950s which at the same time allowed restoration of the stomach's function as a gastric food reservoir $[47,48]$. Prospective studies have indeed confirmed the efficacy of this anti-reflux procedure, however other adverse consequences are diarrhoea or halitosis and no gains in QoL nor in other nutritional parameters over other technically much simpler ways of reconstructing; this now leading a decreased popularity of this method [49].

In assessing QoL after TG, a significant problem is that it is the size of meals consumed that often prolongs the period of convalescence. The next step in the development of gastric surgery was thereby focused on reconstructing the gastrointestinal tract so that a food reservoir was created. For the aforementioned reconstruction methods, only the ileo-caecal segment fulfils this role. Just as reconstruction without food reservoirs, such methods can be divided into two groups according to whether duodenal passage is retained or not. In 1952, Hunt and Lawrence were the first to

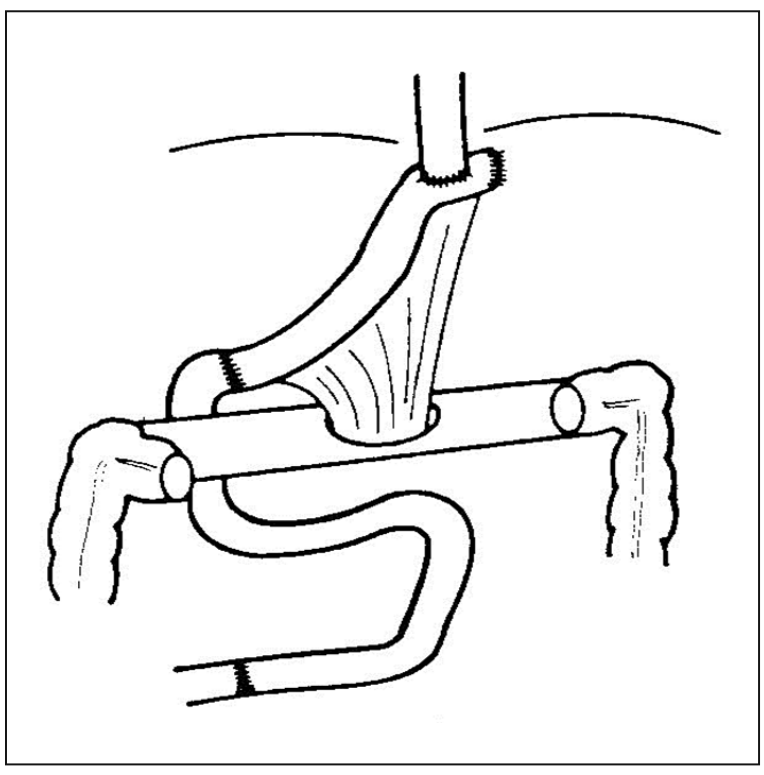

Figure 3. Longmire-Henley reconstruction. Duodenal passage retained

propose creating a J-shaped reservoir (J-Pouch) which did not preserve duodenal passage, but was modified in 1976 by Herfarth through the jejunoplication anastomosis; this still being successfully used up till now [50-52]. Reconstructions that create an intestinal reservoir by duodenal closure were also suggested by Tomoda and Nakayama [53] whilst Lygidakis proposed avoiding intestinal dilation and slowing passage by forming two reservoirs separated by a $5 \mathrm{~cm}$ segment without anastomosis [54]. Horwath proposed creating a $15 \mathrm{~cm}$ long reservoir with two anti-peristaltic anastomised loops forming a Y-shaped pouch (i.e. aboral pouch) [55]. Methods for constructing food reservoirs are more complex and time consuming, and thereby require extensive experience in gastric surgery by the surgeon. Upon reviewing the literature, the observed effects of improving QoL and nutritional parameters in patients after TG for reconstruction without any reservoirs do not meet the desired outcomes. Thus, reconstructions using R-Y methods and L-H interpositions are still the simplest and most commonly used methods for restoring the continuity of the gastrointestinal tract after TG.

\section{Minimally invasive surgery}

Access via minimally invasive surgery was pioneered using GC surgery at a Japanese centre. The first laparoscopy-assisted distal gastric resection was performed in 1994 Kitano et al. [56], and the first TG (due to cancer) by Azagra et al. (Belgium) in 1995 [57]. At present, using laparoscopy is uncontroversial when making pre-operative diagnoses of gastric cancer particularly in advanced disease stages. According to NCCN recommendations, using laparoscopy for diagnostic purposes are made in cases whenever diagnos- 
ing T3-4 or $\mathrm{N}+$ tumours is in any doubt. At lower stages of clinical advancement, the chances of diagnosing metastases is low ( $4 \%$ vs $25 \%$ ), even when aided by laparoscopic-ultrasound examination; Power et al. [58]. Laparoscopic access in GC surgery is slowly gaining more and more adherents. Nevertheless it is difficult to unequivocally address all concerns about minimally invasive surgery because most publications report short series cases.

For this reason, both ESMO and NCCN recommends that minimally invasive access requires further prospective studies for due consideration. Husher et al. [59] reported on the first prospective study which compared open techniques in conjunction with laparoscopy to distal gastrectomy [59]. Long-term results have shown no differences in OS, but have however demonstrated shorter hospital stays, reduced blood loss and the starting of oral nutrition earlier for those undergoing laparoscopy. Controversies abound on questions concerning the completeness of resection as well as that of regional lymphadenectomy with local recurrences occurring or implants in such areas after trocar puncture. Laparoscopic gastric surgery undoubtedly requires the surgeon to be extensively experienced. Initially, such surgical access was preferred when dealing with less advanced (T1-T2) tumours in the distal part of the stomach. This procedure is widely supported in Japan, where the incidence of contracting early gastric cancer (EGC) reaches $50 \%$. Concerns over retaining a QoL are reasons for considering wedge resection for Tis or T1 a tumours, although for such patients endoscopic dissection can also be a surgical treatment option [60-62]. For T1b tumours located in the body of the stomach, wedge resection is considered while maintaining the prepyloric area, gastro-intestinal anastomosis and D1 lymphadenectomy [63]. In Japan in 2010, $42 \%$ of SGs are performed through laparoscopic access [64]. It is currently believed that minimally invasive surgery can also used in more advanced cases [65-68], where its outcomes largely depend on the experience of the centre. Some practitioners tend to gain laparoscopic access using a port for lending the hand assistance, especially that the wound needed for removal has a similar size $[69,70]$. The risk of local recurrence or implants in the post-trocar channel occurs mainly in advanced cases and can be limited by an appropriate surgical technique. It should be remembered though that laparoscopic access cannot reduce the oncological extent of the resection.

\section{Conclusions}

In spite of the progress made in other areas of oncology, the surgeon and the quality of their experience are still the only sure guarantee for treating GC. The effectiveness of combination therapy does not obviate the surgeon of responsibility for resecting to the correct extent (partial or total gastric removal with at least a $5 \mathrm{~cm}$ macroscopically healthy margin) taking into account regional lymph nodes removal (D2 lymphadenectomy excepting T1N0-D1 tumours). Minimally invasive access, if keeping to oncological standards, is equivalent to open cancer surgery, particularly for less advanced tumours of the distal stomach. A correct/ /appropriate reconstruction of the digestive tract still remains a determinant for the QoL after TG.

\section{Conflicts of interest: none declared}

\section{Tomasz Olesiński, MD, PhD}

Department of Oncological Gastroenterology

Maria Sklodowska-Curie Memorial Cancer Center

and Institute of Oncology

Roentgena 5, 02-781 Warszawa, Poland

e-mail:tolesinski@coi.waw.pl

Received: 25 Apr 2016

Accepted: 10 Jun 2016

\section{References}

1. Ferlay J, Shin HR, Bray F et al. GLOBOCAN 2008 v 1. 2. Cancer Incidence and Mortality Worldwide: IARC CancerBase No 10. Lyon, France: International Agency for Research on Cancer. 2010; http://globocan. iarc.fr>.

2. Wojciechowska U, Didkowska J, Zatoński W. Cancer in Poland 2012, Warszawa: Krajowy Rejestr Nowotworów (onkologia.org.pl).

3. European Union Network of Excellence (EUNE) for Gastric Cancer Steering Group. Gastric cancer in Europe. Br J Surg 2008; 95: 406-408.

4. de Angelis R, Sant M, Coleman MP et al. Cancer survival in Europe 1999-2007 by country and age: results of EUROCARE-5-a population-based study. Lancet Oncol 2014; 15: 23-34.

5. Henley FA. Gastrectomy with replacement: Hunterian lecture delivered at the Royal College of Surgeons of England on 31st March, 1953. Ann R Coll Surg Engl 1953; 13: 141-160.

6. Thorwald J. Stulecie chirurgów. Warszawa: Społeczny Instytut Wydawniczy Znak, 2008; 405-477.

7. Finney JM. The development of surgery of the stomach: with special reference to the part played by American surgeons. Ann Surg 1929; 90: 829-846.

8. Macintyre IM, Akoh JA. Improving survival in gastric cancer: review of operative mortality in English language publications from 1970. Br J Surg 1991; 78: 771-776.

9. Orr TG. A modified technic for total gastrectomy. Trans West Surg Assoc 1948; 54: 172-179.

10. Diaz De Liano A, Oteiza Martinez F, Ciga MA et al. Impact of surgical procedure for gastric cancer on quality of life. Br J Surg 2003; 90: 91-94.

11. Bozzetti F. Principles of surgical radicality in the treatment of gastric cancer. Surg Oncol Clin North Am 2001; 10: 833-854.

12. Davies J, Johnston $\mathrm{D}$, Sue-Ling $\mathrm{H}$ et al. Total or subtotal gastrectomy for gastric carcinoma? A study of quality of life. World J Surg 1998; 22: 1048-1055.

13. Gouzi JL, Huguier M, Fagniez PL et al. Total versus subtotal gastrectomy for adenocarcinoma of the gastric antrum. A French prospective controlled study. Ann Surg 1989; 209: 162-166.

14. Bozzetti F, Marubini E, Bonfanti G et al. Subtotal versus total gastrectomy for gastric cancer: five-year survival rates in a multicenter randomized Italian trial. Italian Gastrointestinal Tumor Study Group. Ann Surg 1999; 230: 170-178.

15. Pierie J, Ott M. Gastric cancer. In: Cameron J (ed). Current surgical therapy, wyd. 7. St. Louis: Mosby; 2001: 105-112.

16. Brar SS, Mahar AL, Helyer LK et al. Processes of care in the multidisciplinary treatment of gastric cancer: results of a RAND/UCLA expert panel. JAMA Surg 2014; 149: 18-25.

17. Hundahl SA, Phillips JL, Menck HR. The National Cancer Data Base Report on poor survival of US gastric carcinoma patients treated with gastrectomy: fifth edition American Joint Committee on Cancer staging, proximal disease, and the "different disease" hypothesis. Cancer 2000; 88: 921-932. 
18. Siewert JR, Böttcher K, Stein HJ et al. Relevant prognostic factors in gastric cancer: ten-year results of the German Gastric Cancer Study. Ann Surg 1998; 228: 449-461.

19. Bonenkamp J, Hermans J, Sasako $M$ et al. Extended lymph-node dissection for gastric cancer. Dutch Gastric Cancer Group. N Engl J Med 1999; 340: 908-914.

20. Cuschieri A, Weeden S, Fielding J et al. Patient survival after D1 and D2 resections for gastric cancer: long-term results of the MRC randomized surgical trial. Surgical Co-operative Group. Br J Cancer 1999; 79: 1522-1530.

21. Kasakura Y, Fujii M, Mochizuki F et al. Is there a benefit of pancreaticosplenectomy with gastrectomy for advanced gastric cancer? Am J Surg 2000; 179: 237-242.

22. Shchepotin IB, Chorny V, Hanfelt J et al. Paliative superselective intraarterial chemotherapy for advanced nonresectable gastric cancer. $J$ Gastrointest Surg 1999; 3: 426-431.

23. D'Amato A, Santella S, Cristaldi M et al. The role of extended total gastrectomy in advanced gastric cancer. Hepatogastroenterology 2004; 51: 609-612.

24. Martin RC 2nd, Jaques DP, Brennan MF et al. Extended local resection for advanced gastric cancer: increased survival versus increased morbidity. Ann Surg 2002; 236: 159-165.

25. Maruyama K, Okabayashi K, Kinoshita T. Progress in gastric cancer surgery in Japan and its limits of radicality. World J Surg 1987; 11:418-425.

26. Edwards P, Blackshaw GR, Lewis WG et al. Prospective comparison of D1 vs modified D2 gastrectomy for carcinoma. Br J Cancer 2004; 90 : 1888-1892.

27. Hartgrink $\mathrm{HH}$, van de Velde $\mathrm{CJ}$, Putter $\mathrm{H}$ et al. Extended lymph node dissection for gastric cancer: who may benefit? Final results of the randomized Dutch gastric cancer group trial. J Clin Oncol 2004; 22: 2069-2077.

28. Otsuji E, Toma A, Kobayashi S et al. Outcome of prophylactic radical lymphadenectomy with gastrectomy in patients with early gastric carcinoma without lymph node metastasis. Cancer 2000; 89: 1425-1430.

29. Sano T, Sasako M, Yamamoto $S$ et al. Gastric cancer surgery: morbidity and mortality results from a prospective randomized controlled trial comparing D2 and extended para-aortic lymphadenectomy — Japan Clinical Oncology Group study 9501. J Clin Oncol 2004; 22: 2767-2773.

30. Kulig J, Popiela T, Kolodziejczyk P et al. Standard D2 versus extended D2 (D2+) lymphadenectomy for gastric cancer: an interim safety analysis of a multicenter, randomized, clinical trial. Am J Surg 2007; 193: 10-15.

31. Isozaki H, Okajima K, Fujii K et al. Effectiveness of paraaortic lymph node dissection for advanced gastric cancer. Hepatogastroenterology 1999; 46: 549-554.

32. Ajani JA, Bentrem DJ, Besh S et al. Gastric cancer, version 2.2013: featured updates to the NCCN Guidelines. J Natl Compr Canc Netw 2013; 11: 531-546.

33. Okines A, Verheij M, Allum W et al. Gastric cancer: ESMO Clinical Practice Guidelines for diagnosis, treatment and follow-up. Ann Oncol 2010; 21 Suppl 5: v50-v54.

34. Japanese gastric cancer treatment guidelines 2010 (ver. 3); Japanese Gastric Cancer Association. Gastric Cancer 2011; 14: 113-123.

35. Morrow D, Passaro ER. Alkaline reflux esophagitis after total gastrectomy. Am J Surg 1976; 132: 287-291.

36. Nier $\mathrm{H}$, Wienbeck $\mathrm{H}$, Berges $\mathrm{W}$ et al. Syndromes after total gastrectomy with special respect to esophageal reflux. Langenbecks Arch Chir 1983; 360: 71-80.

37. Nakayama K. Evaluation of the various operative methods for total gastrectomy. Surgery 1956; 40: 488-502.

38. Longmire WP Jr, Beal JM. Construction of a substitute gastric reservoir following total gastrectomy. Ann Surg 1952; 135: 637-645.

39. Longmire WP. Total gastrectomy for carcinoma of the stomach. Surg Gynecol Obstet 1947; 84: 21-30.

40. Yang YS, Chen LQ, Yan XX et al. Preservation versus non-preservation of the duodenal passage following total gastrectomy: a systematic review. J Gastrointest Surg 2013; 17: 877-886.

41. Pan $Y, L i ~ Q$, Wang DC et al. Beneficial effects of jejunal continuity and duodenal food passage after total gastrectomy: a retrospective study of 704 patients. Eur J Surg Oncol 2008; 34: 17-22.

42. Lawrence W Jr. Reconstruction after total gastrectomy: what is preferred technique? J Surg Oncol 1996; 63: 215-220.
43. Gutgemann A, Schreiber HW, Bartsh WM. The shape and function of the post-gastrectomy substitute stomach. Med Welt 1966; 15: 752-756.

44. Siewert JR, Böttcher K. Esophagojejunoplication with the stapler technique. Results of a controlled study. Langenbecks Arch Chir 1992; 377: 186-189.

45. Siewert JR, Peiper HJ. Clinical results of oesophagojejunoplication: a special reconstructive procedure after total gastrectomy. Surg Gastroenterol 1982; 1: 55-62.

46. Górka Z, Wojtyczka A, Lampe P et al. Całkowite wycięcie żołądka sposobem Longmire'a i Roux. Ocena inwaginacyjnej techniki zespolenia przełykowo-jelitowego. Wiad Lek 1997; 50: 394-400.

47. Lee CM Jr. Transposition of a colon segment as a gastric reservoir after total gastrectomy. Surg Gynecol Obstet 1951; 92: 456-465.

48. Hunnicutt AJ. Replacing stomach after total gastrectomy with right ileocolon. AMA Arch Surg 1952; 65: 1-11.

49. Sakamoto T, Fujimaki M, Tazawa K. lleocolon interposition as a substitute stomach after total or proximal gastrectomy. Ann Surg 1997; 226: 139-145.

50. Hunt CJ, Cope JS. Modified technic for total gastrectomy with formation of a food pouch from the jejunum. Am Surg 1952; 18: 85-90.

51. Lawrence W. Reservoir construction after total gastrectomy: an instructive case. Ann Surg 1962; 155: 191-198.

52. Herfarth C, Schlag P, Buhl K. Surgical procedures for gastric substitution. World J Surg 1987; 11: 689-698.

53. Nakayama K. Evaluation of various surgical technics for total gastrectomy. Chirurg 1955; 26: 266-272.

54. Lygidakis NJ. Total gastrectomy for gastric carcinoma: a retrospective study of different procedures and assessment of a new technique of gastric reconstruction. Br J Surg 1981; 68: 649-655.

55. Horváth OP, Kalmár K, Cseke L et al. Nutritional and life-quality consequences of aboral pouch construction after total gastrectomy: a randomized, controlled study. Eur J Surg Oncol 2001; 27: 558-563.

56. Kitano S, Iso Y, Moriyama M et al. Laparoscopy-assisted Billroth I gastrectomy. Surg Laparosc Endosc 1994; 4: 146-148.

57. Azagra JS, Goergen M, Gilbart E et al. Laparoscopy-assisted total gastrectomy with extended lymphadenectomy for cancer: technical aspects. Le Jour Coeliochir 2001; 40: 35-36.

58. Power DG, Schattner MA, Gerdes $\mathrm{H}$ et al. Endoscopic ultrasound can improve the selection for laparoscopy in patients with localized gastric cancer. J Am Coll Surg 2009; 208: 173-178.

59. Huscher CG, Mingoli A, Sgarzini G et al. Laparoscopic versus open subtotal gastrectomy for distal gastric cancer: five-year results of a randomized prospective trial. Ann Surg 2005; 241: 232-237.

60. Nozaki I, Kubo Y, Kurita A et al. Long-term outcome after laparoscopic wedge resection for early gastric cancer. Surg Endosc 2008; 22: 2665-2669.

61. Ludwig K, Klautke G, Bernhard J et al. Minimally invasive and local treatment for mucosal early gastric cancer. Surg Endosc 2005; 19: 1362-1366.

62. Kobayashi T, Kazui T, Kimura T. Surgical local resection for early gastric cancer. Surg Laparosc Endosc Percutan Tech 2003; 13: 299-303.

63. Lee SW, Nomura E, Bouras G et al. Long-term oncologic outcomes from laparoscopic gastrectomy for gastric cancer: a single-center experience of 601 consecutive resections. J Am Coll Surg 2010; 211: 33-40.

64. Yasunaga $\mathrm{H}, \mathrm{H}$ origuchi $\mathrm{H}$, Kuwabara Ket al. Outcomes after laparoscopic or open distal gastrectomy for early-stage gastric cancer: a propensitymatched analysis. Ann Surg 2013; 257: 640-646.

65. Tanimura S, HigashinoM, FukunagaY et al. Laparoscopic gastrectomy with regional lymph node dissection for upper gastric cancer. Br J Surg 2007; 94: 204-207.

66. Huang JL, Wei HB, Zheng ZH et al. Laparoscopy-assisted D2 radical distal gastrectomy for advanced gastric cancer. Dig Surg 2010; 27: 291-296.

67. Park DJ, Han SU, Hyung WJ et al. Long-term outcomes after laparoscopy assisted gastrectomy for advanced gastric cancer: a large-scale multicenter retrospective study. Surg Endosc 2012; 26: 1548-1553.

68. Hamabe $\mathrm{A}$, Omori $\mathrm{T}$, Tanaka $\mathrm{K}$ et al. Comparison of long-term results between laparoscopy-assisted gastrectomy and open gastrectomy with D2 lymph node dissection for advanced gastric cancer. Surg Endosc 2012; 26: 1702-1709.

69. Sakuramoto S, Kikuchi S, Kuroyama S et al. Laparoscopy-assisted distal gastrectomy for early gastric cancer: experience with 111 consecutive patients. Surg Endosc 2006; 20: 55-60.

70. Kim YW, Bae JM, Lee JH et al. The role of hand-assisted laparoscopic distal gastrectomy for distal gastric cancer. Surg Endosc 2005; 19: 29-33. 